\title{
STRUCTURAL BEHAVIOR OF PHOENIX DACTYLIFERA L. FIBERS REINFORCED CONCRETE
}

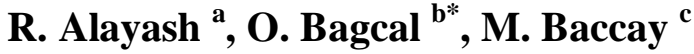 \\ ${ }^{a}$ Ministry of Energy, Baghdad, Iraq, e-mail: rasha_alayash@yahoo.com \\ b* School of Engineering, Tarleton State University, Stephenville, TX, USA, e-mail: bagcal@ tarleton.edu \\ ${ }^{c}$ Department of Civil Engineering, Technological University of the Philippines, Ayala Blvd., Manila, e-mail: melito_baccay@tup.edu.ph
}

Received: 31.03.2020 / Accepted: 12.04.2020/ Revised: 23.07.2020 / Available online: 15.12.2020

DOI: $10.2478 /$ jaes-2020-0016

KEY WORDS: concrete, fiber, fracture, matrix, mechanical properties, void.

\begin{abstract}
:
The continuous demands for stringent environmental regulation and increased interests in the preservation of natural resources have motivated industries and research institutions to examine and consider alternative approaches on the use of renewable resources and waste by-products. This study was conducted using one of the most available natural fiber types worldwide, the Phoenix Dactylifera L. Fibers, commonly known as Date Palm Fibers (DPF). Limited researches and inconsistencies in results obtained have been reported in literature on the use of DPF in concrete. Thus, there is a need of further evaluation and study on the structural behavior of fiber reinforced concrete with DPF. The present study used DPF as a natural reinforcement in concrete at varying content of $0 \%, 0.6 \%, 1.0 \%$, and $1.4 \%$; and different fiber lengths of $0 \mathrm{~mm}, 15 \mathrm{~mm}, 30 \mathrm{~mm}$, and $45 \mathrm{~mm}$. The results indicated that integration of DPF affects the physical properties particularly the workability and density of fresh concrete. Generally, the mechanical properties such as compressive strength, tensile strength, and flexural strength of DPF reinforced concrete decreases as the amount of DPF increases in content and fiber lengths. Scanning Electron Microscopy (SEM) analysis was carried out to examine the internal behavior and effect of DPF in the hardened concrete. Matrix deboning, fiber fractures, and voids due to the pull-out effect were observed as failure modes that contributed to lower compressive strength, tensile strength, flexural strength, and deflection as compared to control specimen.
\end{abstract}

\section{INTRODUCTION}

In recent years, the use of industrial and agricultural by-products as alternative cement-based construction materials has been the subject of research and studies around the world, particularly in developing countries. The utilization of these by-products has demonstrated various advantages not only for providing sustainable alternatives and for approaches in disposing of wastes, but also improving and enhancing the engineering properties of the concrete material in terms of both the physical and mechanical properties. Moreover, the continuous demands for stringent environmental regulation and increased interests in the preservation of natural resources have motivated industries and research institutions to examine and consider alternative approaches to the use of renewable resources and waste byproducts.

Phoenix Dactylifera L. Fibers, commonly known as Date Palm Fibers (DPF), are considered one of the most available natural fiber types worldwide. Large quantities of date palm biomass waste are accumulated annually without proper utilization (ALOqla et al., 2014). It is estimated that there are 150 million date palm trees spread over an area of 1.3 million hectares in 30 countries (Hassan, 2012).
Further, among the natural fibers, agricultural by-products obtained from date palm trees are one of the most abundant sources in the world and are good candidates for admixture that possibly enhances the properties of cement-based materials (Tioua et al., 2017). In most cases, many of these by-products were discarded or burned after harvest. However, natural fibers are renewable and low-cost resources that can be used as a substitute for non-renewable raw building materials as constituents in concrete and can help reduce construction costs and provide eco-friendly alternatives. Natural fiber can be explored and considered as admixture in concrete that can be beneficial for developing countries to help lower the cost of construction materials (Alatshan et al., 2017).

Concrete is considered the most widely used construction material in the world. The importance of concrete in modern society cannot be underestimated. In fact, the use of concrete worldwide is estimated at more than one ton of concrete is produced every year per person (Neuwald, 2004). Concrete is not only used in building construction but also in other structures such as bridges, road constructions, harbors, and other uses. The use of additives is one of the technological advances in enhancing the quality and engineering properties of concrete.

\footnotetext{
* Corresponding author: Orlando R. Bagcal, Ph.D., CGP, Assistant Professor, Construction Science and Management, School of Engineering, Tarleton State University | Member of the Texas A\&M University System, 201 St Felix St., Box T-0400, Stephenville, TX 76402, e-mail: bagcal@tarleton.edu | Tel.: 254- 968-9253.
} 
An additive is a substance added to fresh concrete in small quantities to improve its properties. One of the most important additives is fiber (Subramani, 2007). Recent studies in which concrete reinforced with different natural fibers such as coconut, bamboo, sisal, etc. (Agrawal, Dhase and Agrawal, 2014; Domke, 2012) has been the subject or topic in responding to sustainable cost-effective building construction (Parveen, Rana, and Fangueiro, 2012).

Interestingly, very few research studies have been reported in literature about the use of DPF in concrete as well as inconsistencies in the results obtained (Alatshan et al., 2017; Makhroufi, 2014; Tioua et al., 2017). A limited number of published studies have shown that natural fibers can provide benefits for early age properties (Tioua et al., 2017). According to Alatshan, et al. (2017) that the addition of DPF in concrete showed a clear improvement in flexural strength as well as an increase in compressive strength. The result of the study conducted by Makhroufi (2014), however, is in contradiction to the result obtained by Alatshan, et al. (2017). Makhroufi reported that the addition of DPF in concrete reduced the compressive strength. Additionally, a study conducted by Djoudi, et al. (2012) revealed that some vibration is essential to get suitable workability and compaction of DPF concrete. Djoudi, et al. also concluded that the presence of DPF in concrete improves its mechanical properties. They further argued that excessive fiber content resulted in the reduction of both compressive and flexural strength. Kumar et al. (2010) contended that different fibers change the properties of Fiber Reinforced Concrete (FRC) depending on the type of fiber materials, geometric orientation, distribution, and densities.

In view on the variation of the mechanical effects of DPF in concrete as well as to support sustainable construction, this study was undertaken to provide potential interest in using DPF in concrete as an alternative low-cost sustainable construction material. Further, understanding the physical and mechanical properties and behavior of fiber reinforced concrete is required to analyze and evaluate its effect and optimization on the structural performance. This study was conducted to examine the influence of DPF as a natural additive in concrete particularly for its physical and mechanical properties, and structural behavior. Additionally, the effect of the fiber lengths and various proportions of DPF in the concrete mixture on the structural behavior were considered. However, the effect of surface treatment of DPF was not considered in this study. Specifically, this study aimed to achieve the following:

1. To determine the effects of date palm fibers on the physical properties of fresh concrete;

2. To determine the effects of varying proportions and lengths of date palm fibers on the mechanical properties of hardened concrete (compressive strength, split tensile strength, flexural strength and modulus of rupture); and

3. To determine the influence of fiber length and fiber content on the concrete matrix structure using scanning electron microscopy (SEM).

\section{MATERIALS AND METHODS}

\subsection{Project Structure}

Fiber reinforced concrete (FRC) is concrete containing fibrous material which alters or enhances the physical and mechanical properties of fresh and hardened concrete. The American Concrete Institute (ACI) (2002) defined FRC as concrete containing dispersed, randomly oriented fibers. To evaluate the effects of DPF in concrete mixtures for both fresh and hardened state, an experimental study was employed. DPF was incorporated in the concrete mixtures at varying percentages and fiber lengths. The water-cement ratio used was 0.5 for all mixtures for non-air-entrained concrete. The minimum design compressive strength of the concrete in accordance with ACI requirement is $21 \mathrm{MPa}$ at 28 days curing. The physical properties of DPF used in the study were tested and analyzed. The concrete mixing followed the ACI 211 procedure. The physical and mechanical properties of the concrete mixture were tested and evaluated following the ASTM procedures. The experimental study consisted of 60 cylindrical specimens with dimensions of $100 \mathrm{~mm}$ diameter $\mathrm{x} 200 \mathrm{~mm}$ high for compressive and split tensile strength tests; and 30 prisms, $100 \mathrm{~mm} \times 100 \mathrm{~mm} \mathrm{x} 400 \mathrm{~mm}$ in dimensions, for the modulus of rupture tests. A scanning electron microscopy (SEM) was performed for nine prisms after a flexural strength test to evaluate the effect of varying fiber lengths and content on the mechanical properties, matrix deboning, and presence of voids due to fiber pull-out. The specimens were casted and cured for 28 days prior to testing.

\subsection{Materials}

The date palm fibers (DPF) were obtained in Baghdad, Iraq. The fibers used as shown in Figure 1 were in the form of ropes commonly available at commercial stores in the city and it is pretreated using sodium hydroxide solution to enhanced the tensile strength and lessen the presence of hemicellulose content. The fibers were cut in three different lengths: $0 \mathrm{~mm}, 15 \mathrm{~mm}, 30 \mathrm{~mm}$, and $45 \mathrm{~mm}$. The fiber content added to the mixture varied from $0 \%, 0.6 \%, 1.0 \%$, and $1.4 \%$ by volume of cement. The DPF mixtures were taken into account to determine the considerable variation on the mechanical effects of DPF at a smaller increment of $0.4 \%$ as compared to $0.5 \%$ reported in literature to further characterize the influence of DPF in concrete. The physical properties of the DPF was analyzed and evaluated. The results are presented in Table 1. The other concrete components such as cement and aggregates were tested and the physical properties were determined. The Portland cement used in this study was Type I with specific gravity of 3.15. The coarse aggregates were crushed gravel with maximum size of $25 \mathrm{~mm}$ and used as Saturated Surface Dry (SSD) for mixing. The absorption rate was $0.7 \%$ and specific gravity was 2.83 . The dry rodded unit weight was obtained as $1570 \mathrm{~kg} / \mathrm{m}^{3}$.

The fine aggregate had a maximum size of $4.75 \mathrm{~mm}$, specific gravity of 2.62 , and absorption rate of $1.1 \%$. The fineness modulus obtained was 2.6 and used as SSD for mixing. Potable water was used in mixing the concrete. 


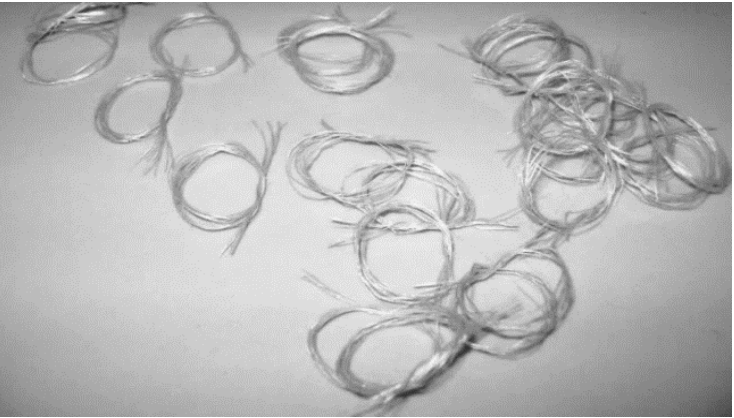

Figure 1. Coiled Phoenix Dactyliferous L. Fibers (Date Palm Fibers) were cut into different fiber lengths

\begin{tabular}{cc}
\hline Properties & Result \\
\hline Diameter $(\mathrm{mm})$ & 0.20 \\
\hline Tensile Strength $\left(\mathrm{kgf} / \mathrm{m}^{2}\right)$ & 27.06 \\
\hline Elongation $(\%)$ & 4.32 \\
\hline Density $\left(\mathrm{kg} / \mathrm{m}^{3}\right)$ & 1159 \\
\hline Specific Gravity & 1.159 \\
\hline Absorption $(\%)$ & 49.6 \\
\hline
\end{tabular}

Table 1. Date palm fibers properties

\subsection{Testing}

Testing for the physical properties of the fresh concrete mixture were in accordance with ASTM procedure as shown in Table 2.

\begin{tabular}{cc}
\hline Properties & Testing Procedure \\
\hline Unit Weight & ASTM C138 \\
\hline Yield Volume & ASTM C138 \\
\hline Air Content & ASTM C138 \\
\hline Slump & ASTM C143 \\
\hline
\end{tabular}

Table 2. Physical properties testing used in this study

Testing for the mechanical properties of hardened concrete is shown in Table 3 . The compressive strength, split tensile strength, and flexural strength were calculated using Formulas 1, 2, and 3 respectively. The prisms were subjected to a center point loading using the compression machine with 10 tons capacity. The scanning electron microscopy (SEM) was performed at high magnifications using JFC-1200 Fine Coater Machine.

\begin{tabular}{cc}
\hline Properties & Testing Procedure \\
\hline Compressive Strength & ASTM C595 \\
\hline Split Tensile Strength & ASTM C496 \\
\hline Flexural Strength & ASTM C293 \\
\hline
\end{tabular}

Table 3. Mechanical properties testing used in this study

$$
\begin{aligned}
& f^{\prime} C=\frac{P}{A} \\
& f_{T}=\frac{2 P}{\pi L d}
\end{aligned}
$$

$$
f_{R}=\frac{3 P L}{2 b d^{2}}
$$

where: $f^{\prime} c=$ Compression strength $(\mathrm{MPa}), f_{\mathrm{T}}=$ Tensile strength $(\mathrm{MPa}), f_{\mathrm{R}}=$ Modulus of Rupture (MPa), $\mathrm{P}=$ Applied load at the moment specimen failure in Newton $(\mathrm{N}), \mathrm{A}=$ Cross sectional area $\left(\mathrm{mm}^{2}\right), \mathrm{L}=$ length of the specimen in $(\mathrm{mm}), \mathrm{d}=$ diameter of the specimen in $(\mathrm{mm}), \mathrm{b}=$ beam width $(\mathrm{mm})$.

\subsection{Mix Design and Proportions}

The mix proportions of DPF and other materials are given in Table 4. The other materials such as fine and coarse aggregates, and water requirements were determined based on the ACI 211 method. The $0 \%$ DPF content and $0 \mathrm{~mm}$ fiber length served as the control specimen.

Fresh concrete mixtures with various amounts and lengths of DPF were prepared and evaluated to determine the physical and mechanical properties. The concrete mixtures were cast in a cylindrical shaped metal or in a non-absorbent material (such as PVC pipe) and a rectangular prism for the flexural test. The cylindrical specimens and prisms were cured for 28 days. The hardened concretes were tested to determine their mechanical

\begin{tabular}{|c|c|c|c|c|c|c|c|c|}
\hline \multirow[b]{2}{*}{ ID } & \multirow[b]{2}{*}{ w/c } & \multicolumn{4}{|c|}{ Concrete Component (kg) } & \multicolumn{3}{|c|}{ Date Palm Fiber } \\
\hline & & $\mathrm{W}$ & $\mathrm{C}$ & CA & FA & $\begin{array}{l}\text { DPF } \\
(\mathrm{kg})\end{array}$ & $\begin{array}{c}\text { DPF } \\
\text { Length } \\
(\mathrm{mm})\end{array}$ & $\begin{array}{c}\text { DPF } \\
\text { Volume } \\
(\% \text { of } C)\end{array}$ \\
\hline A1 & \multirow{3}{*}{0.5} & \multirow{3}{*}{225} & \multirow{3}{*}{450} & \multirow{3}{*}{1005} & \multirow{3}{*}{720} & \multirow{3}{*}{0} & \multirow{3}{*}{0} & \multirow{3}{*}{0} \\
\hline $\mathrm{A} 2$ & & & & & & & & \\
\hline A3 & & & & & & & & \\
\hline A1I & \multirow{3}{*}{0.5} & \multirow{3}{*}{225} & \multirow{3}{*}{450} & \multirow{3}{*}{1005} & \multirow{3}{*}{720} & \multirow{3}{*}{0.43} & \multirow{3}{*}{15} & \multirow{3}{*}{0.6} \\
\hline A2I & & & & & & & & \\
\hline A3I & & & & & & & & \\
\hline A1II & \multirow{3}{*}{0.5} & \multirow{3}{*}{225} & \multirow{3}{*}{450} & \multirow{3}{*}{1005} & \multirow{3}{*}{720} & \multirow{3}{*}{0.715} & \multirow{3}{*}{30} & \multirow{3}{*}{1} \\
\hline A2II & & & & & & & & \\
\hline A3II & & & & & & & & \\
\hline A1III & \multirow{3}{*}{0.5} & & & & & & & \\
\hline A2III & & 225 & 450 & 1005 & 720 & 1 & 45 & 1.4 \\
\hline A3III & & & & & & & & \\
\hline B1I & & & & & & & & \\
\hline B2I & 0.5 & 225 & 450 & 1005 & 720 & 0.43 & 15 & 0.6 \\
\hline B3I & & & & & & & & \\
\hline B1II & & & & & & & & \\
\hline B2II & 0.5 & 225 & 450 & 1005 & 720 & 0.715 & 30 & 1 \\
\hline B3II & & & & & & & & \\
\hline B1III & & & & & & & & \\
\hline B2III & 0.5 & 225 & 450 & 1005 & 720 & 1 & 45 & 1.4 \\
\hline B3III & & & & & & & & \\
\hline C1I & & & & & & & & \\
\hline $\mathrm{C} 2 \mathrm{I}$ & 0.5 & 225 & 450 & 1005 & 720 & 0.43 & 15 & 0.6 \\
\hline C3I & & & & & & & & \\
\hline C1II & & & & & & & & \\
\hline C2II & 0.5 & 225 & 450 & 1005 & 720 & 0.715 & 30 & 1 \\
\hline C3II & & & & & & & & \\
\hline C1III & & & & & & & & \\
\hline C2III & 0.5 & 225 & 450 & 1005 & 720 & 1 & 45 & 1.4 \\
\hline C3III & & & & & & & & \\
\hline
\end{tabular}
properties such as compressive strength, split tensile strength and flexural strength. There were nine specimens tested for SEM.

Table 4. Material mix proportion of various specimen 


\section{RESULTS AND DISCUSSIONS}

\subsection{Physical Properties}

Results of the slump tests revealed that the addition of date palm fibers in fresh concrete significantly affected the workability of concrete as shown in Table 5. The highest slump height of $98 \mathrm{~mm}$ was observed in the control mix with no fiber content exhibiting a very high workable mixture. On the other hand, the addition of increasing amount of fibers at constant water- cement ratio resulted in lower slumps ranging from 22 to $78 \mathrm{~mm}$. The slump test results clearly signified that the workability of DPF reinforced concrete decreases as the amount and length of fibers increases.

\begin{tabular}{lllll}
\hline ID & $\begin{array}{c}\text { DPF } \\
\text { Content } \\
(\boldsymbol{\%})\end{array}$ & $\begin{array}{c}\text { DPF } \\
\text { Length } \\
(\mathbf{m m})\end{array}$ & $\begin{array}{c}\text { Slump } \\
(\mathbf{m m})\end{array}$ & $\begin{array}{c}\text { Density } \\
\left(\mathbf{k g} / \mathbf{m}^{\mathbf{3}}\right)\end{array}$ \\
\hline A & 0 & 0 & 98 & 2535 \\
\hline AI & 0.6 & 15 & 78 & 2417 \\
\hline AII & 1 & 15 & 39 & 2284 \\
\hline AIII & 1.4 & 15 & 30 & 2113 \\
\hline BI & 0.6 & 30 & 75 & 2385 \\
\hline BII & 1 & 30 & 40 & 2174 \\
\hline BIII & 1.4 & 30 & 25 & 2051 \\
\hline CI & 0.6 & 45 & 69 & 2383 \\
\hline CII & 1 & 45 & 38 & 2328 \\
\hline CIII & 1.4 & 45 & 22 & 2217 \\
\hline
\end{tabular}

Table 5. Physical properties of concrete: Slump and Density Tests

The addition of DPF in the concrete mixtures affected the density of concrete as shown in Table 5. It was observed that the density of concrete reinforced with DPF decreased as the amount of DPF increased. The increasing amount of DPF in the concrete causes the concrete mixture to be lighter as expected since the DPF specific gravity was lower than the other constituents. It can be observed that the specimen with $1.4 \%$ DPF at $30 \mathrm{~mm}$ fiber length recorded the highest decrease in density at $19 \%$ as compared to the control specimen. The lower slump height and density in the DPF concrete mixtures could be attributed to the ability of the DPF to absorb some of the water component in the mixture, thus, reduces the workability and lower density. This observation is consistent to the study conducted by Joseph et al (2003) on sisal reinforced concrete in which they concluded that the presence of hemicellulose content in the fiber and fiber with hollow cavities resulted in light weight, low density, increase moisture absorption, and fiber swelling.

It was further observed that the presence of DPF in the concrete mixtures increased the cohesiveness making the mixture less workable. This condition is due to the DPF specific surface, water absorption, and surface texture properties which affect the workability of the concrete mixtures. Consequently, the concrete with DPF generated more air voids entrapped in the mixture, thus decreasing the density of the concrete mixtures and requiring increased consolidation during the mixing and casting process. This observation is in agreement with the study conducted by Djoudi, et al. (2012) and Ramli and Hoe (2010).

\subsection{Mechanical Properties and Structural Behavior}

\subsubsection{Compressive Strength of Concrete}

The compressive strength results are shown in Figure 2. The compressive strength of the control specimen is higher than the specimens with DPF. The compressive strength of the specimen with $15 \mathrm{~mm}$ fiber length and contents of $0.6 \%, 1 \%$, and $1.4 \%$ decreased by $17 \%, 46 \%$, and $69 \%$ respectively while the compressive strength of the specimen with $30 \mathrm{~mm}$ fiber length decreased by $31 \%, 58 \%$, and $73 \%$ respectively. On the other hand, the compressive strength obtained in the $45 \mathrm{~mm}$ specimen decreased by $26 \%, 43 \%$, and $59 \%$ respectively. The results showed that the compressive strength was slightly affected by the length of the date palm fibers due to the voids created by fibers, which weakened the concrete specimen with DPF content.

However, the concrete mixtures with $0.6 \%$ at varying fiber lengths of $15 \mathrm{~mm}, 30 \mathrm{~mm}$, and $45 \mathrm{~mm}$ attained compressive strengths of $33.42 \mathrm{MPa}, 27.73 \mathrm{MPa}$, and $29.71 \mathrm{MPa}$ respectively which exceeded the required design strength of $21 \mathrm{MPa}$ at 28 days of curing. The concrete mixture with $1 \% \mathrm{DPF}$ at $15 \mathrm{~mm}$ and 45 $\mathrm{mm}$ fiber length achieved compressive strengths of $21.78 \mathrm{MPa}$ and 23.02 MPa respectively at 28 days curing and were within the required design strength. It was further observed that concrete with longer DPF provided additional hold during the compression test but at a short period while the shortest fiber length $(15 \mathrm{~mm})$ exhibited optimum contribution in the concrete strength.

The reduction of compressive strengths in the concrete with DPF can be attributed to the decreasing effectiveness of the crosssectional area of the concrete specimen due to the spaces occupied by the fibers. A study conducted by Soulioti et al. (2011) where the addition of fibers to the concrete mixtures created a more difficult consolidation process, thus increasing entrapped air. As the amount of DPF content increased, the compressive strength decreased in all fiber length considered.
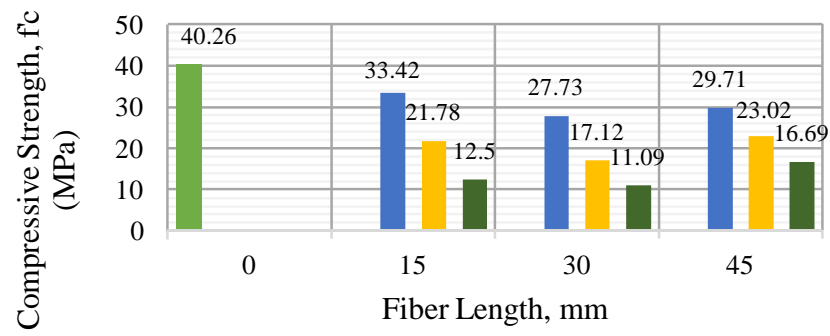

$$
\text { a Control } \quad \square .60 \% \quad \square 1.00 \% \quad \square 1.40 \%
$$

Figure 2. Compressive strength of fiber reinforced concrete with DPF with varying DPF content and fiber length

\subsubsection{Split Tensile Strength of Concrete}

The split tensile strength results of the concrete at 28 days curing are shown in Figure 3. The results indicated that the various lengths of fiber affected the split tensile strength of concrete with DPF. The DPF concrete with $0.6 \%$ at $15 \mathrm{~mm}$ fiber length recorded the highest split tensile strength at 3.9 MPa but less than the control specimen by $25 \%$. The DPF concrete with $1 \%$ and 
$1.4 \%$ at $15 \mathrm{~mm}$ fiber length were lower by $50 \%$ and $58 \%$ respectively as compared to the control specimen. The lowest tensile strength recorded was $1.89 \mathrm{MPa}$ with DPF of $1.4 \%$ at 30 mm fiber length.

The DPF was expected to bridge the cracks in the matrix; however, there seemed to be dissipation in strength due to early pull out and deboning of fibers that caused a decrease in tensile strength. The DPF concrete with $1.4 \%$ exhibited a development of more cracks due to the existence of an increased amount of fibers. This observation strengthens the result obtained by Balaguru et al. (1992) in which they argued that the fibers had no effect on the tensile strength of the matrix, until after the matrix cracked and then the fibers could bridge the cracks. It was further observed that the presence of DPF in concrete bridged the micro cracks and controlled the fracture.

Gencel et al. (2011) indicated that when the tensile stress is transferred to the fibers, the transfer restricted the propagation of the macro cracks and substantially improved the splitting tensile strength of the concrete. Generally, the split tensile strength decreased with the increasing amount of DPF in all fiber lengths.

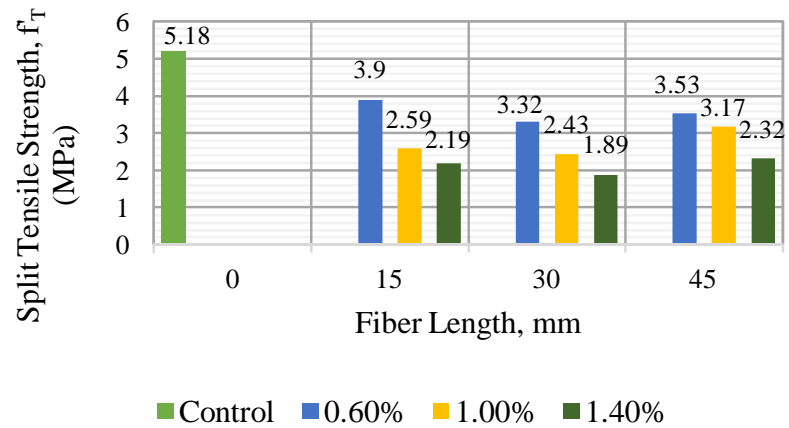

Figure 3. Split tensile strength of fiber reinforced concrete with DPF with varying DPF content and fiber length

\subsubsection{Modulus of Rupture of Concrete}

A prismatic beam was subjected to center point loading. The monitoring of load and deflection were observed carefully until the failure and cracks were achieved. The tests were undertaken in accordance with ASTM C293. The results on the effect of fiber lengths for the modulus of rupture on the concrete are shown in Figure 4.

The results showed that the highest modulus of rupture was observed in the specimen with $15 \mathrm{~mm}$ fiber length containing $0.6 \%$ DPF. As compared to the control specimen, there is a slight reduction in the flexural strength by $2 \%$.

The specimen with $1 \%$ and $1.4 \%$ DPF at $15 \mathrm{~mm}$ fiber length showed a reduction of $20 \%$ and $44 \%$ respectively as compared to the control specimen. Moreover, for the $30 \mathrm{~mm}$ fiber length with $0.6 \%, 1 \%$, and $1.4 \%$ DPF content decreased by $34 \%, 43 \%$, and $53 \%$ respectively while the $45 \mathrm{~mm}$ fiber length with $0.6 \%, 1 \%$, and $1.4 \%$ DPF decreased by $23 \%, 26 \%$, and $45 \%$ respectively.

It was further observed that the specimen with $45 \mathrm{~mm}$ fiber length and different DPF content have modulus of rupture that were

higher than the flexural strength of specimens with $30 \mathrm{~mm}$ fiber length. This can be attributed to considerable ductility in the concrete which was observed after cracking when sufficient fibers were present. It was observed that specimen that do not pull-out or fracture immediately upon the application of load but undergo pull-out behavior thereafter increased in flexural strength.

As loading progressed, stresses were transferred to the fiber network and pull-out of the fiber started to develop within the DPF reinforced concrete causing it to break or crash. Filho et al. (1999) asserted that this observation becomes the important mode of behavior, which governs the flexural failure.

ACI 201 indicated that the modulus of rupture is equal to $10 \%$ of the specified compressive strength. In this study, the modulus of rupture for the control specimen was $13 \%$ of the specified compression strength while DPF concrete with $0.6 \%$ content at 15 mm fiber length was $15 \%$ of its compressive strength.

Generally, the mechanical properties of DPF concrete specimens were lower as compared to the control specimen.

This condition can be explained by the ability of the DPF to absorb some water that slowed the hydration process, thus reduces the mechanical characteristics obtained especially with higher amount of DPF.

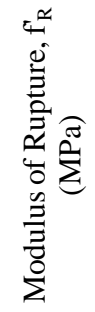

$$
\left(\frac{10}{0}\right.
$$$$
0
$$

Fiber Length, mm

$$
\text { -Control } \quad \square .60 \% \quad \square 1.00 \% \quad \square 1.40 \%
$$

Figure 4. Modulus of Rupture of fiber reinforced concrete with DPF with varying DPF content and fiber length

\subsubsection{Deflection of Concrete}

The effect of the date palm fiber was analyzed through the load deflection graphs to show the flexural capacity for several beams simultaneously while flexural testing was conducted.

As shown in Figure 5, the DPF with $15 \mathrm{~mm}$ fiber length recorded the lowest load capacity at failure and decreased as the amount of DPF increased.

Figure 6 show that the DPF reinforced concrete with $15 \mathrm{~mm}$ fiber length at $0.6 \%$ fiber content logged the highest deflection of 2.7 $\mathrm{mm}$.

The $30 \mathrm{~mm}$ fiber length at $0.6 \%$ fiber content failed at a deflection of $2.1 \mathrm{~mm}$ at a load of $8759 \mathrm{~N}$ while the $45 \mathrm{~mm}$ fiber length with the same content sustained a load of $9,686 \mathrm{~N}$ at a deflection of $2.45 \mathrm{~mm}$. Further, the $30 \mathrm{~mm}$ fiber length experienced a sudden cracking. 
The DPF reinforced concrete with $15 \mathrm{~mm}$ fiber length at $0.6 \%$ content recorded the highest load capacity at $11,370 \mathrm{~N}$.

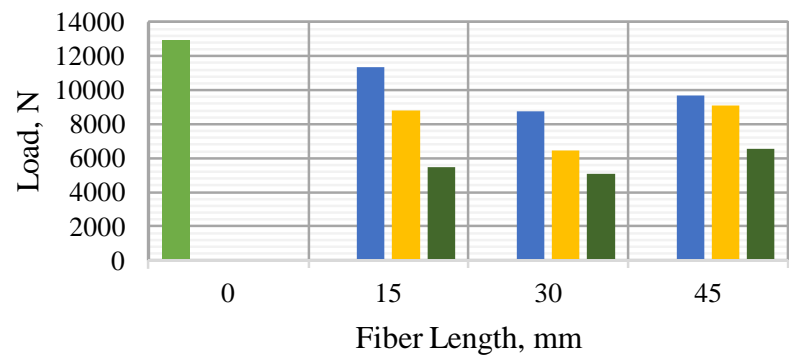

- Control $\quad-0.60 \% \quad \square 1.00 \% \quad \square 1.40 \%$

Figure 5. Applied load for deflection testing of fiber reinforced concrete with DPF at the moment specimen fractured

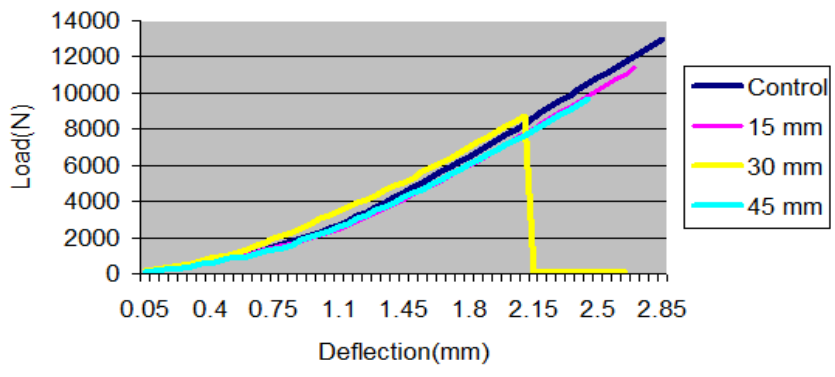

Figure 6. Deflection effect of $0.6 \%$ DPF reinforced concrete

The $15 \mathrm{~mm}$ and $30 \mathrm{~mm}$ fiber length at 1.0\% DPF content experienced a sudden crack as shown in Figure 7.

The $15 \mathrm{~mm}$ fiber length recorded a deflection of $2.4 \mathrm{~mm}$ at a load of $8,801 \mathrm{~N}$ while the $30 \mathrm{~mm}$ fiber length sustained a load of 6,443 $\mathrm{N}$ with a deflection of $1.85 \mathrm{~mm}$. The $45 \mathrm{~mm}$ fiber length reached a load of $9096 \mathrm{~N}$ with $2.55 \mathrm{~mm}$ deflection at failure which was the highest result obtained within this group.

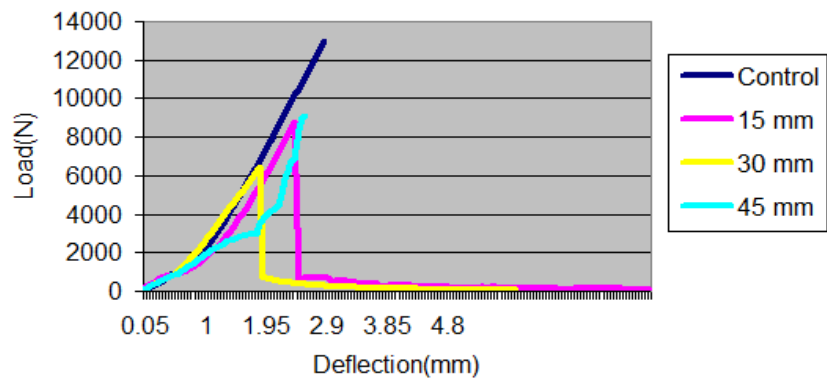

Figure 7. Deflection effect of 1.0\% DPF reinforced concrete

It can be observed in Figure 8 that DPF with $1.4 \%$ content resulted in lower loads as compared to the control specimen.

The higher amount of DPF in the concrete contributed to higher deflections as compared to the $0.6 \%$ and $1.0 \%$ content.
Further, the specimen with $45 \mathrm{~mm}$ attained the highest deflection of $2.75 \mathrm{~mm}$ which provided a good bridge against cracking, but had lower flexural strength as compared to the control specimen.

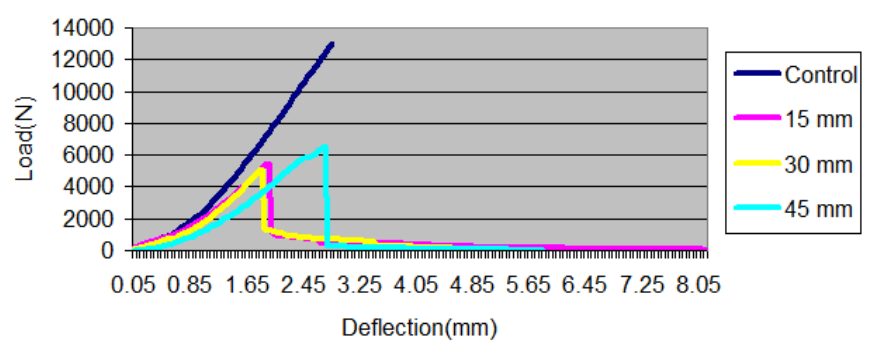

Figure 8. Deflection effect of $1.4 \%$ DPF reinforced concrete

Generally, it can be established that the $45 \mathrm{~mm}$ fiber length regardless of DPF content showed higher deflections and higher load capacities at failure than the other concrete with the DPF concrete mixture. However, the DPF with $45 \mathrm{~mm}$ fiber length while experience sudden cracks as compared to its counterparts, the mixture sustained a longer time before it reached failure. This observation is in agreement with the study of Balaguru \& Shah (1992) in which longer fibers contributed to the sudden cracking effect due to the difference in modulus of elasticity between fibers and the concrete mixture. Additionally, the longer the fiber, the higher the deflection in the concrete beam specimen without causing any sudden failure.

It can be further noted that DPF reinforced concrete has a lesser load carrying capacity as compared to the control specimen. Moreover, the DPF reinforced concrete provided the necessary reinforcement that prevented the immediate crashing or breaking of the specimen while it continued to deflect. This behavior can be attributed to the fiber action that bridges the cracking, thus delaying the breaking of DPF reinforced concrete. Gil (2005) explained in his study on abaca fibers that the addition of natural fibers in concrete applications for members under flexure improved the material's toughness and ductility. This observation is consistent with the study conducted by Jamil (2010) on maguey fibers. Although extra reinforcement was provided by the fibers to prevent sudden failure, the increased amount of fibers caused increase of voids in the concrete. Thus, flexural strength tends to decrease. Walraven (2009) also stated that the differences in strength values of the DPF reinforced concrete are due to the effect of fiber orientation, which is strongly influenced the method of casting and compacting. Vajje and Murthy (2013) explained that with the increase in fiber-concrete ratio, the cracks at failure load were observed to be minimal.

\subsubsection{SEM Analysis on the behavior of DPF Reinforced Concrete}

Scanning Electron Microscopy (SEM) analysis was carried out to examine the internal behavior and effect of DPF in the hardened concrete. Particularly, the fracture and bond characteristics of fiber reinforced concretes were analyzed and evaluated. The SEM specimen were collected from the fractured samples immediately after the flexural strength tests. There were nine cases of different hardened concrete of varying DPF contents of $0.6 \%, 1.0 \%$, and $1.4 \%$; and fiber lengths of $15 \mathrm{~mm}, 30 \mathrm{~mm}$, and $45 \mathrm{~mm}$. The 
parameters considered and examined were fiber pull-out, fractures, and voids. The specimens were all coated with gold for electrical conduction before SEM testing.

It is evident in Figure 9 that the fiber reinforced concrete in all DPF with varying content and fiber lengths showed fiber pull out, breakage, and fracture mechanisms. The strength has decreased with the higher percentage of fiber. The DPF reinforced concrete with $15 \mathrm{~mm}$ fiber length at $1.0 \%$ content had several voids that weakened its strength and thus, caused a sudden failure crack. Matrix deboning, fiber fracture, and voids due to fiber pull out were observed as failure modes.
The SEM image for the $15 \mathrm{~mm}$ fiber with $1.4 \%$ fiber content showed fewer voids as compared to $1.0 \%$ fiber content. The reason for this is that increasing fiber content resulted in a decrease in the fiber pull-out and thus the fiber offered resistance to fractures and absorbed the sudden applied load until failures. Mohankar, et al. (2016) explained that the increased fiber content developed more energy absorption that resulted in an increase in toughness and fracture resistance of the material under cyclic loads. However, in advanced stages of loading, relative displacement took place between the fiber and the concrete matrix, thus frictional stress developed.

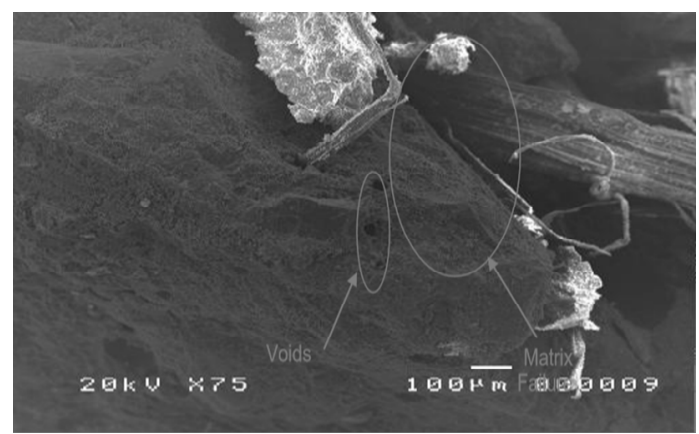

(a) SEM image of $15 \mathrm{~mm}$ at $0.6 \% \mathrm{DPF}$

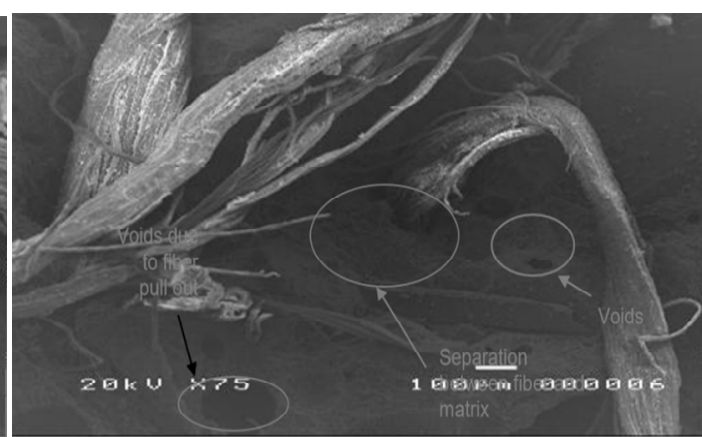

(b) SEM image of $15 \mathrm{~mm}$ at $1.0 \% \mathrm{DPF}$

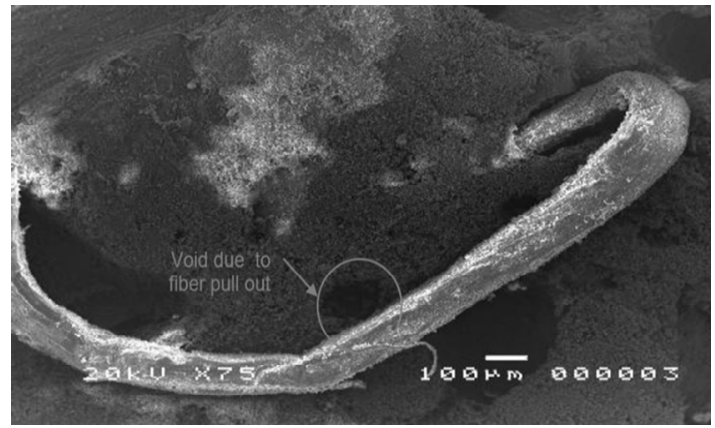

(c) SEM image of $15 \mathrm{~mm}$ at $1.4 \% \mathrm{DPF}$

Figure 9. SEM image of DPF reinforced concrete for $15 \mathrm{~mm}$ fiber length

Figure 10 shows the SEM image of DPF reinforced concrete of 30 $\mathrm{mm}$ fiber length with varying DPF content. It can be observed in the image that there was no maintained interface bonding between the concrete matrix and fibers for the $0.6 \%$ DPF content. It can be seen that there is poor adhesion between the fiber and concrete. Stress transfer between fibers and concrete is only possible to create mechanical interlocking if there is an interface bonding. Therefore, it can be seen that poor interfacial bonding resulted in a decreased strength in the composite (Vidyashankar and Laksmanswamy, 2014).

Several voids were observed for the $1.0 \%$ DPF content with 30 $\mathrm{mm}$ fiber length. The voids were the result of the pulling out of the fibers. The fibers could hold the deflection until the first cracks appeared and then the fibers contributed to preventing sudden failure.
It is evident that a mixed of small voids and large voids were present due to the fiber pull-out. The existence of gaps surrounding the reinforcement generated the poor bonding reinforcement and matrix.

The concrete specimen with $30 \mathrm{~mm}$ fiber length and $1.4 \%$ fiber content revealed an unequal fiber orientation due to the high content of fibers as well as the increased fiber length. Moreover, some matrix failure was noted and more voids occurred due to the increasing fiber length and content, which generated more voids during the mixing process. However, the DPF reinforced concrete provided enough resistance against sudden failure.

The SEM image for the DPF reinforced concrete with $45 \mathrm{~mm}$ fiber length is shown in Figure 11. 
In all DPF content, it is evident that there were fiber pull-out, voids, and fiber fracture which dominated the fractured surface. The specimen with $45 \mathrm{~mm}$ fiber length and $0.6 \%$ DPF content showed visible voids due to fiber pull out that led to reduction of carrying load capacity. It was also observed that the unequal orientation of fibers and the presence of micro cracks weakened the strength properties that led to the fiber pull out when it reached the fibers' roots. The micro cracks increased until adjacent area with greater amounts of fibers were capable of bearing the concentrated stresses at the crack tip. As a result, the strength of the specimen attained and fractures started to grow from the weakest microcrack, thus forming the fracture that would divide the sample in two pieces (Enfedaque et al., 2010).

The DPF reinforced concrete with $1.0 \%$ DPF showed different void sizes which were spread throughout the concrete matrix due to fiber pull out or increasing the fiber amount and length. The voids created a decrease in the bonding property of the concrete, thus decreasing the specimen strength. Just like the specimen with
$0.6 \%$ content with the same fiber length, the parameters that contributed to a lower load carrying capacity and sudden failure were fiber separation from the concrete, fiber fractures, and generation of micro cracks. These parameters weakened the bond between the fiber and the concrete.

Figure 11 (c) shows an unequal orientation of the fibers in some parts and some voids due to fiber pullout similar in effect to the specimen with $45 \mathrm{~mm}$ fiber length $0.6 \%$ and $1.0 \%$ fiber content. It also shows some micro cracks that may affect the strength properties of the concrete. However, the specimen showed a behavior that prevented the occurrence of sudden failure and sustained higher deflection as the loading application progresses. According to Kakooei et al. (2012) the reason for this behavior is due to the fiber's location and the width of the formed crack; thus, a bridge connection was created and the fiber characteristics prevented the separation of concrete pieces after cracking.



(a) SEM image of $30 \mathrm{~mm}$ at $0.6 \% \mathrm{DPF}$

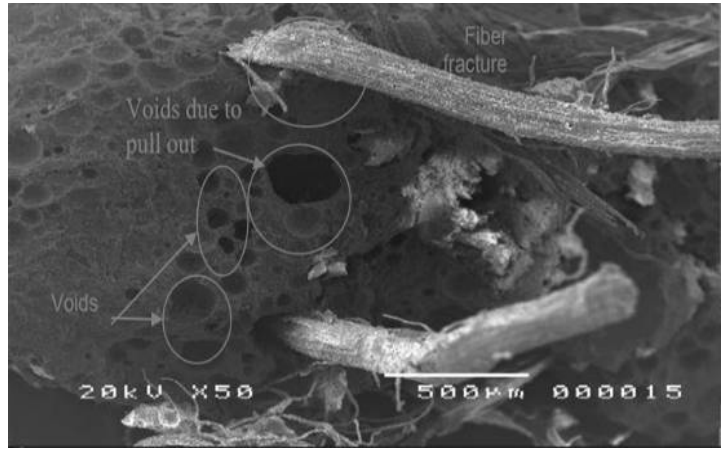

(b) SEM image of $30 \mathrm{~mm}$ at $1.0 \%$ DPF content

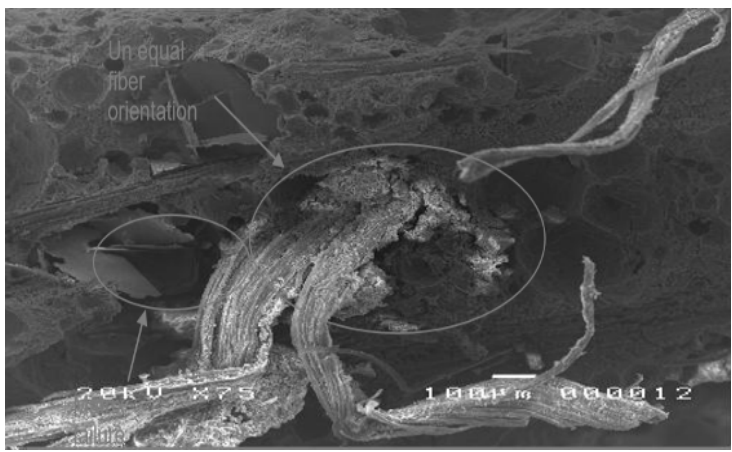

(c) SEM image of $30 \mathrm{~mm}$ at $1.4 \% \mathrm{DPF}$ content

Figure 10. SEM image of DPF reinforced concrete for $30 \mathrm{~mm}$ fiber length 


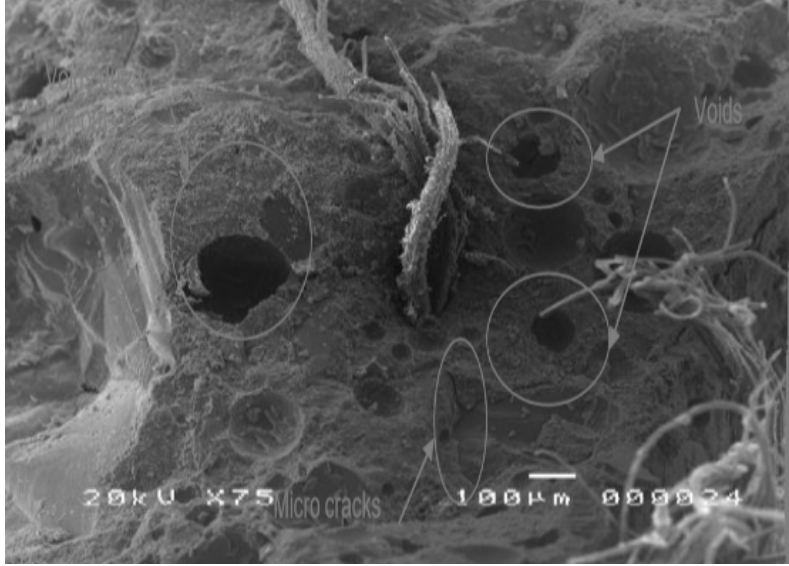

(a) SEM image of $45 \mathrm{~mm}$ at $0.6 \%$ DPF content

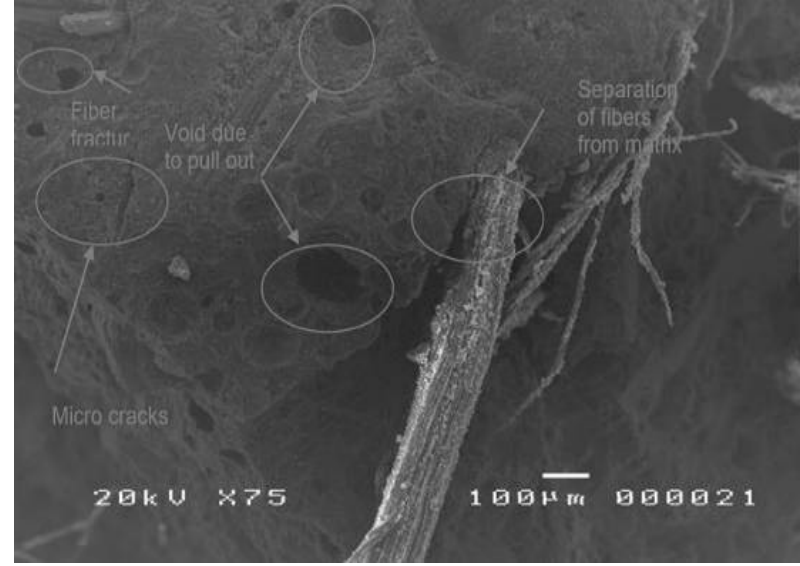

(b) SEM image of $45 \mathrm{~mm}$ at $1.0 \% \mathrm{DPF}$ content

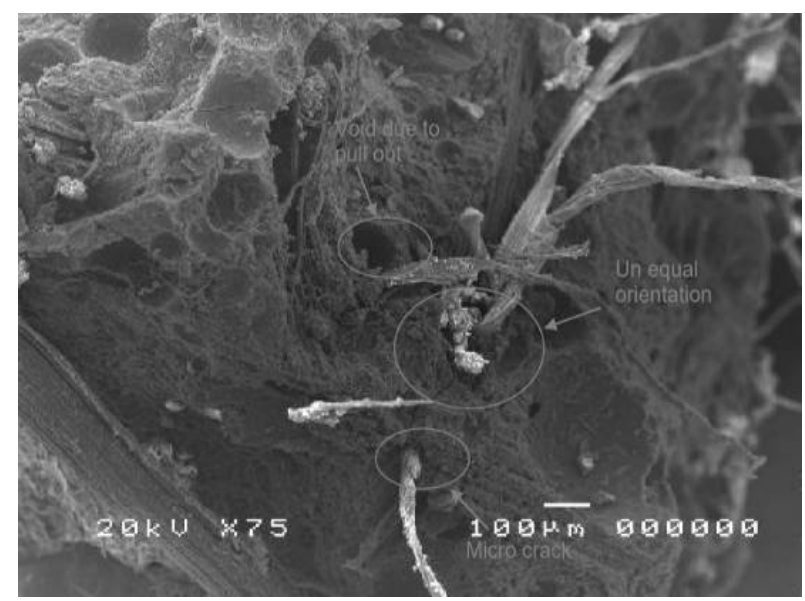

(c) SEM image of $45 \mathrm{~mm}$ at $1.4 \% \mathrm{DPF}$ content

Figure 11. SEM image of DPF reinforced concrete for $45 \mathrm{~mm}$ fiber length

\section{CONCLUSIONS}

Based on the results of the study, the following conclusions were drawn:

1. The inclusion of DPF in concrete mixture affects the workability of fresh concrete. As the amount of DPF content increases, the slump height decreases in all fiber lengths studied. On the other hand, the density of DPF reinforced concrete decreases as the amount and fiber lengths increases due to the lower specific gravity of DPF as compared to the aggregates and cement components.

2. As the amount of DPF content in concrete increases, the compressive strength in all the specimens decreases. The DPF reinforced concrete with $0.6 \%$ content and $15 \mathrm{~mm}$ fiber length recorded the highest compressive strength at 28 days curing of $33.42 \mathrm{MPa}$ which is lower by $17 \%$ as compared to the control specimen. The lowest compressive strength of $11.09 \mathrm{MPa}$ was recorded in the DPF reinforced concrete with $1.4 \%$ content, $30 \mathrm{~mm}$ fiber length. DPF reinforced concrete with $0.6 \%$ content at fiber lengths of $15 \mathrm{~mm}, 30 \mathrm{~mm}$, and $45 \mathrm{~mm}$ as well as for the concrete with $1 \%$ with $15 \mathrm{~mm}$ and $45 \mathrm{~mm}$ fiber lengths exceeded the required design compressive strength of $21 \mathrm{MPa}$.

Increasing the amount of DPF fibers in concrete resulted in decreased split tensile strength in all the specimens. DPF reinforced concrete with $0.6 \%$ at $15 \mathrm{~mm}$ fiber length recorded the highest strength at $3.9 \mathrm{MPa}$. The tensile strength of DPF reinforced concrete with $0.6 \%$ content at $15 \mathrm{~mm}$ fiber length was $15 \%$ of its compressive strength, which is higher than the control specimen by $2 \%$. The flexural strength of DPF reinforced concrete decreased as the amount and length of fiber increased. The highest flexural strength of DPF reinforced concrete was 5.08 MPa for $0.6 \%$ DPF content and $15 \mathrm{~mm}$ fiber length.

3. The DPF reinforced concrete with $45 \mathrm{~mm}$ fiber length in all DPF contents showed higher deflection and higher load capacities as compared to the other DPF reinforced concrete specimens. The highest deflection recorded was $2.75 \mathrm{~mm}$ for DPF content of $1.4 \%$ at $45 \mathrm{~mm}$ fiber length, which is lower than $0.1 \mathrm{~mm}$ as compared to the control specimen. Matrix 
deboning, fiber fracture, and voids due to pull-out effect were observed as the failure modes that contributed to the lower compressive strength, tensile strength, and flexural strength as compared to the control specimen. The DPF served as a temporary crash resistant barrier, which bridged the crack that delayed the breakage and separation of DPF reinforced concrete.

4. The use of DPF as a natural additive in concrete with $0.6 \%$ DPF content at varying lengths of $15 \mathrm{~mm}, 30 \mathrm{~mm}$, and $45 \mathrm{~mm}$ can be utilized for building walls, interior slabs on grade, foundations, and other minor construction works that are not exposed to weather with compressive strengths between the minimum design strength of $21 \mathrm{MPa}$ and $33 \mathrm{MPa}$.

\section{Compliance with ethical standards}

Conflict of Interest Statement. The authors declare that they have no conflict of interest.

\section{References:}

ACI Committee 211, 2002. Standard Practice for Selecting Proportions for Normal, Heavy and Mass Concrete. American Concrete Institute, ACI 211.1-91.

Agrawal RA, Dhase SS, Agrawal KS, 2014. Coconut Fiber in Concrete to Enhance its Strength and Making Lightweight Concrete, International Journal of Engineering Research and Development 9 (8):64-67.

Alatshan F, Altlomate AM, Mashiri F, Alamin W, 2017. Effect of date palm fibers on the mechanical properties of concrete. International Journal of Sustainable Building Technology and Urban Development 8(2):68-80. https://doi.org/doi: $10.12970 /$ susb.20170007.

AL-Oqla FM, Alothman OY, Jawaid M, Sapuan SM, Es-Saheb MH, 2014. Processing and properties of date palm fibers and its composites. In: Hakeem K., Jawaid M., Rashid U. (eds) Biomass and Bioenergy. Springer, Cham. https://doi.org/doi:10.1007/978-3-31907641-6_1.

Balaguru PN, Shah SP, 1992. Fiber-reinforced cement composites. New York: McGraw-Hill.

Djoudi A, Khenfer MM, Bali A, Kadri EH, Debicki G, 2012. Performance of date palm fibres reinforced plaster concrete. International Journal of Physical Sciences 7(21):2845-2853. https://doi: 10.5897/IJPS11.1553.

Domke, PV, 2012. Improvement in the strength of concrete by using industrial and agricultural waste. IOSR Journal of Engineering 2(4):755-759.

Enfedaque A, Cendón D, Gálvez F, Sánchez-Gálvez V, 2010. Analysis of glass fiber reinforced cement (GRC) fracture surfaces. Construction and Building Material 24(7):1302-1308.

Filho RDT, Joseph K, Ghavami K, England G L, 1999. The use of sisal fiber as reinforcement in cement-based composites. Revista Brasileira de Engenharia Agrícola e Ambiental. 3(2):245-256.

Gencel O, Brostowb W, Datashvili T, Thedford M, 2011. Workability and mechanical performance of steel fiber-reinforced self-compacting concrete with fly ash. Composite Interfaces 18:169-184. https://doi.org/doi:10.1163/092764411X567567.
Gil SB, 2005. A study on the abaca fiber reinforced concrete composite. MSCE thesis. Technological University of the Philippines.

Hassan MS, 2012. Bayoud disease on the date palm. First regional conference on pest management of date palm. 23-25 September 2012, Al-Ain, UAE

Jamil MA, 2010. Investigation on the effects of maguey fibers as secondary reinforcement against cracking in concrete beam. MSCE thesis, Technological University of the Philippines.

Joseph PV, Mathew G., Joseph K, Groeninckx G, Thomas S, 2003. Dynamic mechanical properties of short sisal fibre reinforced polypropylene composites. Composites Part A: Applied Science and Manufacturing. 34. 275-290. 10.1016/S1359-835X(02)00020-9.

Kakooei S, Akil HM, Jamshidi M, Rouhi J, 2012. The effects of polypropylene fibers on the properties of reinforced concrete structures. Construction and Building Materials 27: 73-77.

Kumar KR, Mahendran N, Gobinath, R, 2010. Experimental studies on viability of using geosynthetics as fibers in concrete. International Journal of Applied Engineering Research 1(1):15-28.

Makhroufi A, 2014. Contribute to the study of the properties of palm fiber concrete in the dry and warm areas, in Department of Irrigation and Civil Engineering. Kasdi Merbah University Ouargla.

Mohankar RH, Pidurkar MD, Thakre PV, Pakhare SS, 2016. Hybrid Fibre Reinforced Concrete. International Journal of science, Engineering and Technology Research 5(1):1-4.

Neuwald, A, 2004. Supplementary Cementitious Materials, Part I: Pozzolanic SCM's, Precast Inc. Magazine, September/October Issue:9-17.

Parveen S, Rana S, Fangueiro R, 2012. Natural fiber composites for structural applications. In A. J. M. Ferreira \& E. Carrera (Eds). Proceedings of the Mechanics of Nano, Micro and Macro Composite Structures International Conference, Torino, Italy, Politecnico di Torino.

Ramli M, Hoe K W, 2010. Influences of short discrete fibers in high strength concrete with very coarse sand. American Journal of Applied Sciences 7 (12):1572-1578

Tioua T, Kriker A, Barluenga G, Palomar I, 2017. Influence of date palm fiber and shrinkage reducing admixture on self-compacting concrete performance at early age in hot-dry environment. Construction and Building Materials 154(2017):721-733. https://doi.org/doi: 10.1016/j.conbuildmat.2017.07.229.

Soulioti DV, Barkoula NM, Paipetis A, Matikas TE, 2011. Effects of fiber geometry and volume fraction on the flexural behavior of steelfiber reinforced concrete (47):535-541.https://doi.org/ doi: 10.1111/j.1475-1305.2009. 00652.x

Subramani, M, 2007. Palm oil fiber as an additive in concrete. BSC Dissertation, Technology University, Malaysia.

Vajje S, Murthy NR, 2013. Study on addition of the natural fibers into concrete. International Journal of Scientific \& Technology Research 2 (11):213-218

Vidyashankar BV, Laksmanswamy DR, 2014. Experimental investigation of vinylester/ cocount coir /rice husk natural fibers. International Journal of Science and Advanced Technology 4(3):3437.

Walraven JC, 2009. High performance fiber reinforced concrete: progress in knowledge and design codes. Materials and Structures 42:1247-1260. https://doi.org/doi 10.1617/s11527-009-9538-3. 